\title{
Factors affecting School to Work Transition: SARS-CoV 2 Pandemic as a Perception Game Changer
}

\author{
Simona NICOLAE and loana-Ruxandra LIE \\ Economics Department, Faculty of Entrepreneurship, Business Engineering and Management, \\ University POLITEHNICA of Bucharest, Bucharest, Romania
}

Correspondence should be addressed to: loana-Ruxandra LIE; ruxandra.lie@gmail.com

Received date:18 March 2021; Accepted date:25 August 2021; Published date: 18 January 2022

Academic Editor: Lazar Maria Isadora

Copyright (C) 2022. Simona NICOLAE and loana-Ruxandra LIE. Distributed under Creative Commons Attribution 4.0 International CC-BY 4.0

\begin{abstract}
The quality of human inputs of the economic system is conferred primarily by education, but the validation of this quality, at least from the economic point of view, can only be achieved through the labor market. Ensuring the smoothing of the school-to-work transition, even if it is done differently from country to country, is a must have of any functional and efficient economy. But what happens when an economic crisis destabilizes the connection between the two markets, breaking temporarily or permanently the access roads between the education market and the labor market? What happens when the economic crisis turns off the light and the road between the two markets is no longer visible? The paper aims to capture the perception of students on the changes generated by SARS-CoV 2 pandemic on some basic pillars of the school-to-work transition: access to useful and professionally relevant information, the image of the professional profile before and after the beginning of the pandemic, how students intend to make transition from the university to being employed and sources of well-being in an unpredictable and dynamic economy. The data used in our analysis comes from a self-administered questionnaire, that was shared and filled in online by students from the University POLITEHNICA of Bucharest. We conclude with the main findings of our study and their implications, and further directions to assess this issue.
\end{abstract}

Keywords: SARS-CoV 2 pandemic, labor market, education, students' perception

JEL Classification codes: $\mathrm{C} 00$, I23, I28, J01

Cite this Article as: Simona NICOLAE and Ioana-Ruxandra LIE (2022)," Factors affecting School to Work Transition: SARS-CoV 2 Pandemic as a Perception Game Changer", Journal of Eastern Europe Research in Business and Economics Vol. 2022 (2022), Article ID 362300, DOI: 10.5171/2022.362300 


\section{Introduction}

The labor market is an extremely sensitive barometer of any society and can be equally a source and effect of welfare or economic and social imbalances.

Upstream of the labor market is the education market, and downstream, the goods and services market. The economic and health crisis of 2020 short-circuited the links created between the three types of markets, distorting the perception of the main actors on how they function and relate.

The information bubble that was created on each market, but also around each individual, led to blind interactions that did not hint at the effects of economic and social decisions; this isolated and nullified the predictability of actions, from the simplest to the most complex. The individual, as a work resource, has been and still is in the middle of a vortex that tests the maximum biological and professional limits. Locked and isolated physically but forced to adapt to an unprecedented intellectual and emotional dynamic, the human resource was the main character of a static-dynamic paradox that destroyed the harmony and balance between mind and body.

In this context, the paper aims to capture the perception of UPB students on how the SARS-COV 2 pandemic has influenced the following aspects of their lives:

a) Access to useful and professionally relevant information

b) The image of the professional profile before and after the beginning of the pandemic

c) How to achieve the school-work transition

d) Sources of well-being in an unpredictable and dynamic economy

The second section of this paper presents the most important evolutions on the education and labor market, both Romanian and international, because of the SARS-CoV 2 pandemic. The Methodology section presents the data sources for our data and the instruments used in our research and analysis. The next part presents the most important results of the study, while the last one contains the main conclusions, but also some ideas for the development of further research on this topic.

\section{The SARS-CoV 2 Pandemic, the} Education and the Labor Market

\section{The impact of the SARS-CoV 2 pandemic on education}

The SARS-CoV 2 pandemic has affected education more than any other event in human history, forcing the individual to experience both crisis and progress at the same time. The effects generated by the two sides that accompany the present of education, although immediately observable, are difficult to quantify in the long run. We do not yet know to what extent the gains obtained from digitalization will compensate the losses generated by the increase of school dropout and implicitly the social costs that this phenomenon will bring. However, how the pandemic affected education depended heavily on the background that each country had before the beginning of the pandemic, in terms of flexibility and connection to the labor market.

The education market acquires value only in connection with the labor market through the quality of the inputs it provides and through relieving the economy of some social costs; this way, it acts as an anchor for progress.

The SARS-CoV 2 pandemic has affected all education systems worldwide but not equally. The losses will be easier or harder to cover primarily depending on the existence of a strategy that gives education the importance it deserves. 
Educational losses generally have a boomerang effect by taxing societies in terms of efficiency and progress. The great crises, be they economic or otherwise, have always determined turning points in the economic and social evolution of mankind, points beyond which the new reality has brought both benefits and losses. According to an OECD report, while this crisis has deeply disruptive implications, including for education, it does not have predetermined outcomes. It will be the nature of our collective and systemic responses to these disruptions that will determine how we are affected by them (OECD, 2021).

In order to maintain the European social model and social cohesion, it is essential to invest in young people, to promote sustainable and inclusive growth, to address inequalities and to manage migration effectively. Valuing education as a system for sustainable development is the starting point for an efficient and inclusive European construction. In a global competitive environment, where the EU should not compete on low wages, investment in quality education and training (SDG 4) and in young people is crucial to ensure sustainable and inclusive growth. (COM, 2016).

At the EU level, there is a constant concern to ensure a framework for the development and manifestation of human resources, focused on quality education and training. The European Education Area initiative is the main tool on which to build this framework, aimed at promoting common values and a quality of education whose certification should become unitary and add value regardless of the country in which it was carried out.

"The EU enabling framework will foster integration of education and training in the European Semester to reinforce Member States' capacities to recover from the Covid19 crisis. The European Semester will set the broader context in which progress toward achieving the European Education Area will be reviewed alongside other social and economic policies." (COM, 2020)
The impact of the SARS-CoV 2 pandemic was a systemic one which, although it spread worldwide, will first have to be assumed and counteracted at country level. The perception of young people on the imbalances created on the education market is extremely important for the achievement of effective educational policies at home.

Unfortunately, the country report for Romania highlighted the fact that it has entered the economic-sanitary crisis with major problems in the field of education, problems that will have a huge negative effect in the long run on the possibilities of economic recovery and development of the country.

Given that access to quality and inclusive education remains insufficient and no measures have been taken to improve skills, while school results have remained steadily low and early school leaving rates have remained high, equal opportunities for students from poor households, especially in rural areas, and the Roma community, remain an issue. The relevance on the labor market of vocational and technical education, and also the one of higher education remains low and affects graduates' prospects of finding employment (only 69\% of VET graduates are employed compared to the EU average of 79.5\%). No progress has been made in acquiring core and digital skills, but positive results could be achieved if prediction methods are used in order to anticipate future skills needed (E.S., 2020).

Moreover, the percentage of young people who are not employed and do not attend any education or training program is among the highest in the EU, ranking 5th in descending order of NEET percentages, according to data on EUROSTAT.

In this context, knowing students' perception of how the SARS-CoV 2 pandemic has affected their professional future and the chances of capitalizing their knowledge on the labor market is extremely important. Especially since the human resource that is the subject of our analysis is

Simona NICOLAE and Ioana-Ruxandra LIE, Journal of Eastern Europe Research in Business and Economics, DOI: 10.5171/2022.362300 
also the most valuable element in the formation and development of human capital.

\section{The impact of the SARS-CoV 2 pandemic on the labor market}

Although the economic crises in the economic history of the world have taught us what the derived market character of the labor market means, the SARS-CoV 2 pandemic has given us a lesson never seen before: adapting to the negative effects of a crisis whose causes became, temporarily, what Professor Samuelson said about money: the blood that irrigates the economic system. The only difference is that this blood contaminated the economic system by turning the economic car into an economic cart.

Thus, the medical system, a system often ignored in many countries of the world, became the cornerstone and stopped the economic cart in which we all seemed to travel happily, having plenty of snacks earned or borrowed. The effects of this shutdown are very diverse and depend very much on the degree to which each economy has become aware of its vulnerabilities and has tried to mitigate them.

Among the economic markets, the labor market is the one that immediately suffered the effects of this economic and health crisis, radically changing the present and the future of all labor resources. The existence of economic protection measures in this field has helped to reduce the negative impact of the pandemic on the labor market but what has made and will make a difference in the long run is and will be the existing educational strategy both globally and nationally, as it was shown that educated labor resources have a greater resilience to changes that come with economic crises, reducing losses or even registering additional gains in terms of nominal income.

The rates of return to education - which is the differential between the price of highly and less educated workers - may rise during crises, as the earnings of those with less education fall because of increased unemployment rates among this category. This creates a pool of unemployed lesseducated workers, which in turn dampens wages of less-educated workers. If the earnings of the university graduates remain unchanged or change relatively modestly, then the rate of return to university education increases during crises. Also, more educated workers can more easily find other jobs to maintain earnings. Less educated workers tend to take lowerpaying jobs during a crisis, while more advantaged graduates can switch to better jobs more quickly. Employers may be reluctant to lay off educated workers because they are better able to adapt to changing economic conditions. (Fasih et al, 2020).

Besides these possible changes in earnings, the economic crisis caused by the SARS-CoV 2 pandemic created major imbalances in the labor market, as it was accompanied by the need to accelerate the digitization process. A report of the International Labor Organization highlights very clearly these imbalances in terms of job loss / disappearance in some sectors, as well as their growth in other sectors. The latest labor force survey data (up to the third quarter of 2020) reveal the contrast between massive job losses in hard-hit sectors (such as accommodation and food services, arts and culture, retail, and construction) and the positive job growth evident in a number of higher-skilled services sectors (such as information and communication, and financial and insurance activities). This divergence will tend to increase inequality within countries (ILO, 2021).

The concern of labor resources regarding the loss of jobs is also found in 2021. Thus, for the year 2021, on average, $54 \%$ of employed adults from 27 countries say they are concerned about losing their job in the next 12 months $(17 \%$ are very concerned and $37 \%$ somewhat concerned). Globally, $67 \%$ of surveyed employed adults say they can learn and develop skills needed for the jobs of the future through their current employer ( $23 \%$ are very much able to do so, $44 \%$ somewhat able). (Ipsos, 2020) 
At European level, too, the SARS-CoV 2 pandemic has affected the level of employment of labor resources but also their prospects. The most affected were the most vulnerable labor resources, those with a low level of education, low wages, or poor working conditions. Unfortunately, this process will continue in the next period, adding additional pressure to labor resources in vulnerable positions.

According to a report prepared by Fana et al (2020) in the mid-term, we can expect that the economic sectors most affected now will remain problematic until the pandemic is under control, because they involve an important degree of face-to-face social interaction and final (often external) demand. It is thus likely that a very significant proportion of the workers now employed in those sectors will face very uncertain prospects in the medium term, in a context of protracted economic crisis that will provide very thin opportunities in any other way.

Also, between the third quarter of 2019 and the third quarter of 2020, the EU employment rate of young people with a medium educational attainment level decreased from $46 \%$ to $42 \%$. Elementary workers (e.g., cleaners, helpers, laborers in construction and manufacturing, etc.) recorded the sharpest fall in the number of employed people: $-9 \%$, between the third quarter of 2019 and the third quarter of 2020 in the EU. (EUROSTAT, 2021)
In Romania, too, the labor resource was severely affected. According to the EUROFOUND study (2020) in total, 10\% of respondents who were part of the workforce are now out of it. This proportion is largest in Greece and Spain (both 18\%) and Hungary and Romania (both 14\%). The same study reveals that Romania is on the $5^{\text {th }}$ position, in descending order of the possibilities of losing a job in the next 3 months (over 20\%).

Upon entering the economic and health crisis, Romania was in a situation that could not but destabilize the labor market. From the urgent need of 1 million new workers in December 2019, in March, only 2 months and 24 days later, Romania was facing the possibility of reaching to 1 million unemployed. The situation has evolved from a workforce crisis to a shortage of workplaces. Within three months, a difference of 2 million lost workplaces was recorded. (Cindrea, 2020)

Also, examining the resilience at a time of crisis, in July, in the EU as a whole, $14 \%$ of respondents had low resilience, but there are large differences between Member States. The countries with the highest proportion of respondents with low resilience are Bulgaria (21\%), Greece and Hungary (both 20\%), and Romania and Croatia (both 19\%). 


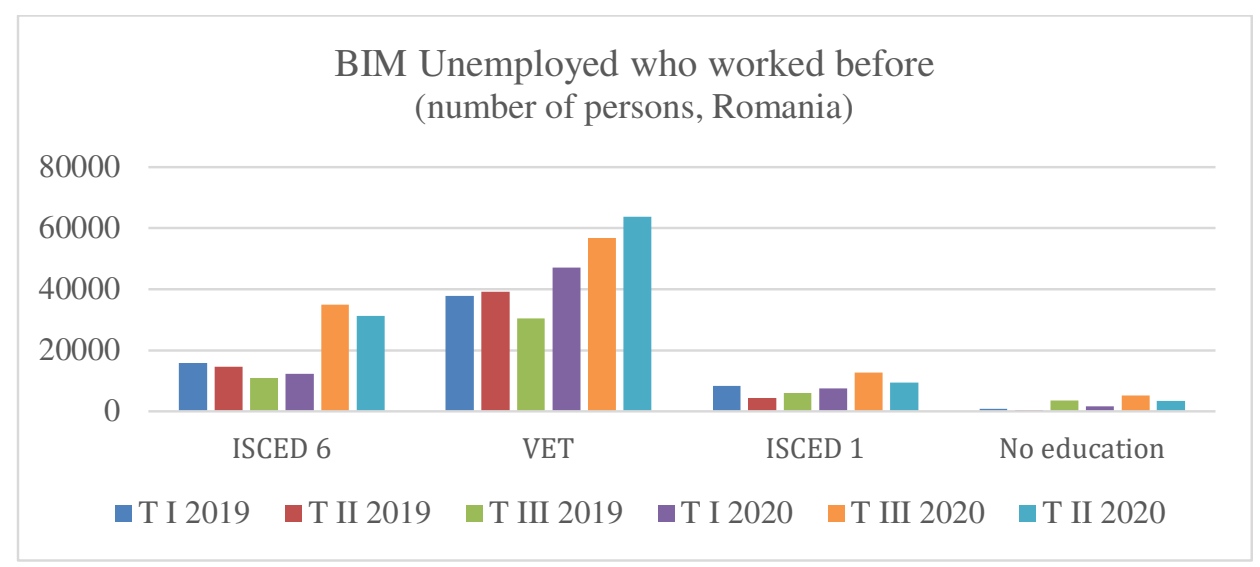

Figure 1: The Unemployed who worked before (Romania) - BIM Statistics Source: The authors based on data from INS, 2020

The number of the unemployed in Romania also had a surprising evolution, growing strongly for graduates who worked before entering the crisis. Between the first quarter of 2020 and the second quarter of 2020 , their increase was $155 \%$, while for those with VET studies, only 35\%. One possible explanation may be that employed labor resources, with higher education, worked in fields with a low degree of digitalization or did not hold a job corresponding to their educational level.

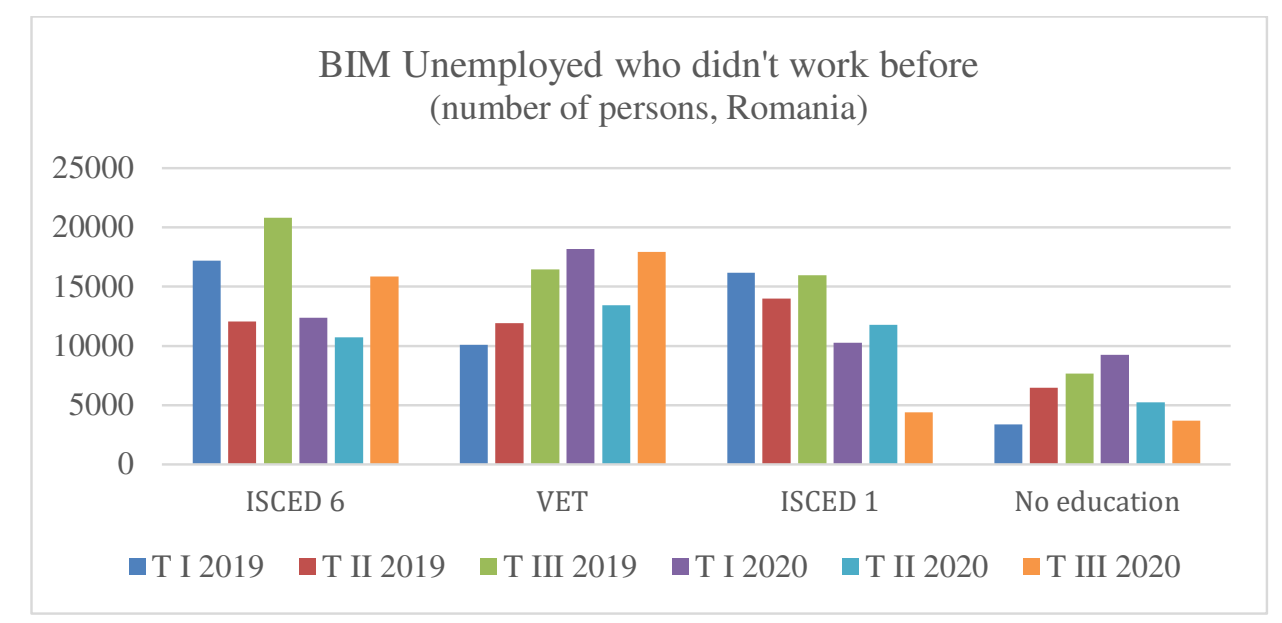

Figure 2: The Unemployed who didn't work before (Romania) - BIM Statistics Source: The authors based on data from INS, 2020

The evolutions registered in Romania support what the European Commission's 2020 Country Report highlights, namely the very small connection between the supply of knowledge in the education and training system and the requirements of the labor

Simona NICOLAE and Ioana-Ruxandra LIE, Journal of Eastern Europe Research in Business and Economics, DOI: 10.5171/2022.362300 
market. The mismatch between the demand and supply of skills has persisted in recent years. The European Competence Index, which measures the performance of EU competence systems, shows that Romania is among the countries with the lowest results, especially in terms of skills development and activation (Cedefop, 2019). In addition, the occurrence of vertical discrepancies (overqualification rate), although still below the EU average, has almost doubled in the last decade. This indicates a widening gap between education and work. (European Commission, 2020)

Taking into account all these developments at international and national level, the aim of this paper is to find out the perception of UPB students on how the SARS-COV 2 pandemic has influenced various aspects of their life, related to the professional area, and to connected areas as well, namely future well-being and prosperity.

\section{Methodology}

The data used in our analysis comes from a self-administered questionnaire, that was shared and filled in online by 133 students from the University POLITEHNICA of Bucharest. $79.7 \%$ of these students are undergraduates, and the rest are studying for their master's degree. Most of them entered the economic-sanitary crisis with a background of expectations and knowledge acquired within the face-to-face interactions. Thus, their answers may be relevant to how their perception of the aspects mentioned before has changed or not.

The questionnaire was administered between the $1^{\text {st }}$ of March 2021 and the $13^{\text {th }}$ of March 2021, about one year from the beginning of the SARS - CoV 2 pandemic.

The objectives that define our research are the following:

- To find which are the most important information sources for students, and also, the value they put on information, and on the channel used to convey it;
- $\quad$ To find if professional perspectives have changed because of the pandemic;

- To find how students intend to make transition from the university to being employed;

- $\quad$ To find what well-being means for students and how they intend to achieve it.

The questions of the questionnaire were questions constructed on the Likert scale, multiple choice questions, and open questions with short answers. In analyzing the data obtained from the questionnaires, we have used descriptive statistics.

\section{Results}

The questionnaire contains four categories of questions that correspond to the four areas we wanted to assess, mentioned previously in this paper.

The first section focuses on the access to information, the students' ability to use it, and on the value of information.

The first two questions of this section are assessing students' perception on the difficulty of understanding the most important subject for their professional future, in online education as opposed to face-to-face courses. The questions were constructed on a Likert scale, where 1 is very difficult, while 5 is very easy. As it can be seen in the graphs below (Figure 3 and 4 ), it seems that more students consider it more difficult to learn online than face to face. We consider that this is a sign that the challenges of the pandemic were addressed, but not completely, and there is still room for improvement in online teaching. On the other hand, changes like the digitalization of education, or students and professors adapting to new styles of education, cannot take place over night; as a consequence, governments and universities should consider other types of security measures that could allow students and professors to come back to class as soon as possible.

Simona NICOLAE and Ioana-Ruxandra LIE, Journal of Eastern Europe Research in Business and Economics, DOI: 10.5171/2022.362300 


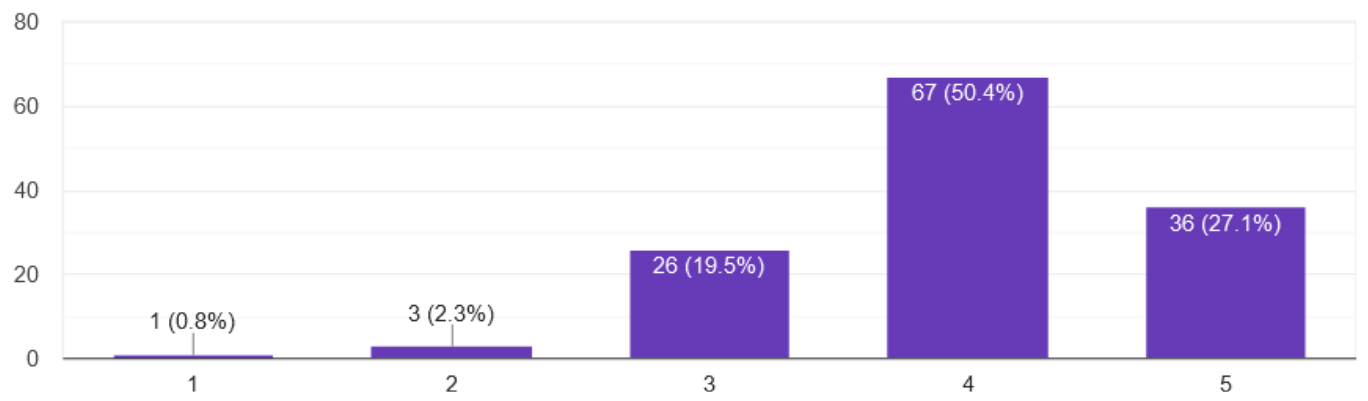

Figure 3: Responses to how easy is understanding the most important subject face to face Source: answers to the questionnaire

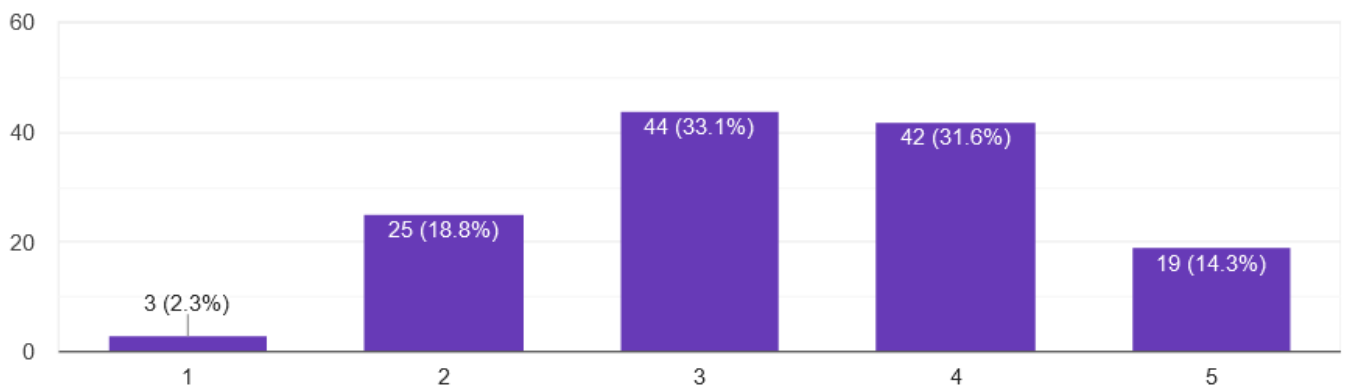

Figure 4: Responses to how easy is understanding the most important subject online Source: answers to the questionnaire

The next step was to find the most trusted sources of information in students' opinion. About $53 \%$ of them place professors on the first place, $37 \%$, the Internet, and $9 \%$, the library. On the second place, around 36\% placed professors, $24 \%$, the Internet, and $38 \%$, the library. For almost $11 \%$ of the students the professors are on the last place, for $38 \%$ the Internet is the last on the list, and for $51 \%$ of them the library is in the last place. As professors, of course, we are pleased to see that the information offered in class is the most trustworthy for most of the students, but, on the other hand, this means a great responsibility - in front of the class one should only present reliable, verified and up to date information. Regarding those who trust most the Internet, it is also the responsibility of the universities to find a way to teach students how to separate reliable information from the fake one, especially nowadays, when classes are online, and the temptation to use the Internet for any doubt is even higher and online sources are even more handy; in fact, this is something that other studies on the generation Z, which includes today's students, have also found (Robert Half, 2015).

The next two questions show that most of the students consider the information received in class as useful and very useful in their future careers, but also, most of them consider that they can manage the information and use it in the future without the help of a professor. This is a concerning discovery, but, on the other hand, we believe this is the perception, and as previous studies have shown, the members of generation $\mathrm{Z}$ tend to overestimate their abilities (Cseh-Papp et al., 2017). 
Finally, we have found that what students appreciate the most about information is its originality (almost 64\%). For the education market, this is an interesting signal, especially in the context of online teaching during the SARS-CoV 2 pandemic: if the courses don't offer interesting and new information, in an interesting way, students' attention will be lost, sometimes, forever.

The second section assesses the view and predictions of students after the beginning of the pandemic, in comparison with their beliefs before it.

Regarding the value they put on the diploma they will obtain, most of the students believe that graduating will increase their chances of finding a job by $50 \%$ or even more than $80 \%$.

If we discuss the professional changes that the pandemic could bring, we were happy to find out that for most of the students the health and economic crisis did not modify the domain they want to work in. This can be due to the fact that nowadays engineers are very sought on the labor market. A more extensive study on students from different universities and domains could show what is the complete picture.

Continuing to discuss the consequences of the SARS-CoV 2 pandemic, it is worth mentioning that the percentage of students who consider themselves disadvantaged by the changes caused by the crises to their chosen domain is equal to the percentage of students who consider that their situation is the same, and these proportions are almost $40 \%$ each. Only the remaining $22 \%$ think that their situation was improved by the pandemic. Again, this perception can be influenced by the high demand for engineers on the labor market, especially when the current situation shows the need for digitalization and technology in our lives.

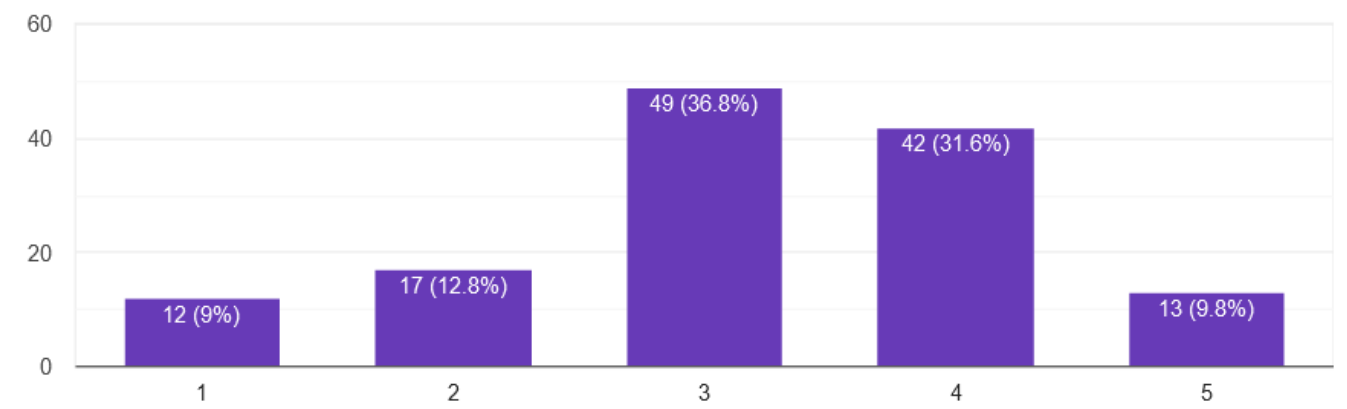

Figure 5: To what extent can an economic or economic-health crisis affect the content of your profession (the requirements and skills needed to fulfill them)? Give marks from 1 to 5 , where $1=$ not at all, and $5=$ radical

Source: answers to the questionnaire

In spite of this encouraging perspective of their profession, on a different question, almost $60 \%$ of the students declared they feel vulnerable professionally when faced with the evolutions in the economy. Moreover, in the last question of this section, almost $44 \%$ of the students consider that the main reason that would cause them to leave a job earlier than planned could be economic crises. The second reason, for a little more than $23 \%$ of the respondents, was the competition between companies, and the third one, with $16.5 \%$ of the answers, was the change in the skills required for a certain job. And, related to required skills, most of the students consider that the competences and requirements of their chosen profession can

Simona NICOLAE and Ioana-Ruxandra LIE, Journal of Eastern Europe Research in Business and Economics, DOI: 10.5171/2022.362300 
be changed from a medium to radical degree by economic or sanitary-economic crises, as it can be seen in Figure 5 .

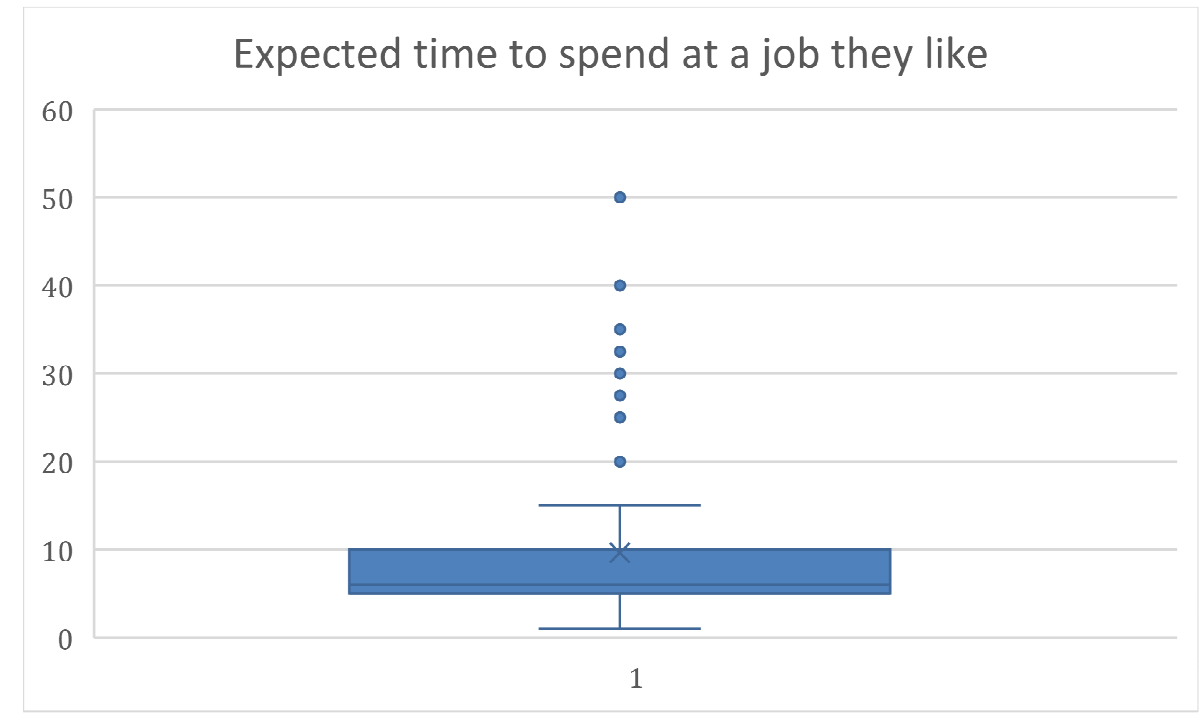

Figure 6: Boxplots of the time students would spend at a job they like Source: authors' calculations based on results of the questionnaire

Regarding the time they would spend at a job, assuming they like it, the median period is of 6 years. There are some who would spend 20 years, or even their entire working life in the same place if they liked it, but they are outliers, as it can be seen in Figure 6. In obtaining these results, we have excluded three answers that were not numerical (the question was an open one, with short answers), where students stated they didn't know what to answer. Also, for those who answered "until I retire", we have changed the answer with an approximation of 40 years.

The third part of the questionnaire focuses on the school - work transition process and students' information regarding the labor market and its challenges.

It is nice to see that almost $28 \%$ of the students, the highest percentage, would choose to contact directly the companies where they would like to work, which involves much more preparation and effort than using an online recruiting platform, that sits on the second position, being chosen by almost $23 \%$ of the respondents. on third place, very close to the second, comes the transition from school to work in the form of starting their own business. In the light of this evolution, as we discussed before, the education market should help these students in their enterprise, by introducing more Economics, Finance and Management courses for all the specializations.

Many students are currently unemployed, slightly more after the pandemic than before it, probably because they were employed in those domains that were mostly affected, as tourism, restaurants etc. This assumption is made based on the fact that before March 2020, 39\% of the students worked in domains that weren't related to their studies, while after the beginning of the pandemic, only $31.6 \%$ still work in domains unrelated to their specialization. An evolution that is worth deeper further study is the fact that before the pandemic, only $11 \%$ of the students worked in their area of study, and after it, in March 2021, this is the situation for $18 \%$ of them.

What is interesting to mention for this section is the fact that students are not very 
aware of the situation of their chosen domain, $82 \%$ of them not knowing which is the unemployment rate in that area. On the other hand, if we discuss their awareness at a general level, a little more than half of them know what are the measures taken by the Romanian Government in order to mitigate the effects of the pandemic on the labor market. Also, it is worth mentioning that many students understand the importance of training and education in recovering from a crisis, supporting our previous idea, that effective education policies are needed to overcome the situation caused by the health and economic crisis: a total of almost $28 \%$ of our respondents consider that the policies aimed at overcoming the crisis should be about supporting people to get a job, and be retrained, if needed, and training.

Regarding the challenges that an economic crisis can bring to the labor market, some students are optimistic, $20 \%$ of them believe they would find a job immediately after graduating. Out of the optimistic group, $37 \%$ are already working on a position related to their studies, and $26 \%$ work in domains unrelated to their education. Only one student believes that it would take more than a year to find a position that fits his education, and he or she is now working in an unrelated domain. For the other categories of answers (1-3 months, 3-6 months, 6-9 months, 9-12 months), we have separated the students regarding their current status (employed in their domain, employed in a different domain, and unemployed), and we found that the mean and median time they expect to spend in finding a job in their area of expertise after graduation is more or less the same, around 4 months, with the unemployed being slightly more optimistic than their colleagues that are already employed.

The last part of our study is dedicated to questions assessing students' view on wellbeing and prosperity.

Here, the results obtained were interesting and encouraging. First of all, most of the students consider that professional success means flexibility (31\%), which is something that the SARS-CoV 2 pandemic has brought by abundance in the labor market, due to digitalization, work from home and the need to balance professional and personal duties from the same space, your own home. Very close to the percentage for flexibility, students also value a motivating salary (27\%), and, ending the top three, the working environment $(21 \%$ of the respondents). Unfortunately, it is clear that the working environment, as we saw it before, will change a lot, especially for those working in positions where work can be done from home. The atmosphere in the office, the interaction with colleagues and management, the little details that made a difference between a good and a bad working environment, are changing or disappearing, which means that students' perception on success, or at least on what a pleasant working environment means, also needs to change. Employers themselves face new challenges in stimulating, evaluating, and rewarding their employees in the new labor market, during and after the SARSCoV 2 pandemic.

Regarding the consequences of the economic and health crisis, very few students think they improved/ significantly affected their perspectives to reach professional success, most of them (54\%) consider that the influence is insignificant. Also, encouraging for Romania's future, nowadays very affected by the emigration of young people from all social categories, and all education levels, most of our students, almost 79\%, consider that professional success can be reached in Romania.

Another important aspect we have found is that most of the students (almost 34\%) consider that the opportunities offered by the economic environment are the decisive factor to reach well-being and prosperity, emphasizing again their view that the current crisis can/will affect their professional and personal lives. And also, to stress previous findings from this questionnaire, on the second place as a decisive factor in reaching well-being and

Simona NICOLAE and Ioana-Ruxandra LIE, Journal of Eastern Europe Research in Business and Economics, DOI: 10.5171/2022.362300 
prosperity, students placed the level of education (almost 29\%), while on the third place they refer again to the economic environment - they chose as a factor the economic stability (almost 22\%). This shows again the importance of training, of education policies adapted to the current social and economic environment, that will offer young generations the skills and knowledge needed for succeeding in their professional and personal lives.

\section{Conclusions}

Labor market and education market are the basis for the development of a society and an economy. Unfortunately, there were also some of the most hit markets because of the SARS-CoV 2 pandemic, even if in a more subtle way than others. They had to face numerous challenges and to adapt quickly to the new, distanced, society. The aim of this paper is to find if and how POLITEHNICA (UPB) students' perception on education, professional future and wellbeing, has changed because of the economic and sanitary crisis, with the help of a selfadministered questionnaire.

We found that more students consider it more difficult to learn online than face to face, and most of them consider their professors as the main source of trustworthy information, followed closely by the Internet, which is a concerning fact, that should lead to finding ways to teach students to discern between real and fake information online. We also discovered that most of the students consider the information received in class as useful and very useful in their future careers, but, unfortunately, they believe they can manage the information and use it in the future without the help of a professor.

It was nice to discover that students believe that graduating will increase their chances of finding a job by $50 \%$ or even more than $80 \%$ and believe that training and education are essential to recover from economic crises; they also consider training and education as factors that influence people's well-being and prosperity. Universities and government should support this belief, by offering educational programs adapted to the current situation and to the prospected evolution of the human society as a whole. This includes also offering more economic, financial and management training, in order to help those who would like to start their own businesses.

In the current health and economic crises, students' perception is they feel vulnerable professionally when faced with the evolutions in the economy and almost 44\% of them consider that the main reason that would cause them to leave a job earlier than planned could be economic crises. Also, they see a link between the economic environment and well-being and prosperity.

A limitation of this study is, nonetheless, the small number of respondents and the fact that they only come from one university. Our further research in this area is intended to include more students, and from different domains of study, in order to see if there are any differences between opinions and expectations, from one area to another. Further studies will also focus on finding if there are differences in perception between undergraduate students and those studying for a master's degree. Also, an evolution that is worth deeper further study is the fact that, before the pandemic, only $11 \%$ of the students worked in their area of study, and after it, in March 2021, this was the situation for $18 \%$ of them.

\section{References}

- Cedefop, (2019), [Online], [Retrieved March 1, 2021] https://skillspanorama.cedefop.europa .eu/en/dashboard/european-skillsindex?pillar $=$ \&country $=$ \&year $=2020 \# 1$

- Cindrea, I, (2020), The labour market crisis in Romania. Causes, effects and potential solutions, Studies in Business and Economics no. 15(1)/2020, DOI 10.2478/sbe-2020-0002, SBE no. 15(1) 2020

- COM, (2016), Communication from the Commission to the European Parliament, the Council, the European Economic and Social Committee and the Committee of the Regions. Next steps for a sustainable European future. European action for sustainability 
[Online], [Retrieved January 15, 2021] https://eur-lex.europa.eu/legalcontent/EN/TXT/?uri=COM\%3A2016 \%3A739\%3AFIN

- $\quad$ COM, (2020), COMMUNICATION FROM THE COMMISSION TO THE EUROPEAN PARLIAMENT, THE COUNCIL, THE EUROPEAN ECONOMIC AND SOCIAL COMMITTEE AND THE COMMITTEE OF THE REGIONS on achieving the European Education Area by 2025, [Online], [Retrieved January 15, 2021] https://eur-lex.europa.eu/legalcontent/EN/TXT/?uri=CELEX\%3A520 20DC0625\&qid=1613562044880

- Comisia Europeană, (2020), [Online], [Retrieved March 1, 2021] https://ec.europa.eu/info/sites/info/fi les/2020-european semester countryreport-romania ro.pdf,

- $\quad$ Csech-Papp, I., Varga, E., Szabo, K., Szira, Z., Hajos, L. (2017). The appearance of a new generation on the labour market, ANNALS of Faculty Engineering Hunedoara - International Journal of Engineering, Tome XV [2017] Fascicule 1, [Online], [Retrieved February 20, 2021] Available at: http://annals.fih.upt.ro/pdffull/2017/ANNALS-2017-1-19.pdf.

- Fana, M., Tolan, S., Torrejón, S., Urzi Brancati, C., Fernández-Macías, E, (2020), The COVID confinement measures and EU labour markets, EUR 30190EN, Publications Office of the European Union, Luxembourg, 2020, ISBN 978-92-79-18812-4 doi:10.2760/079230, JRC12057

- Fasih et all, (2020), The impact of COVID-19 on labor market outcomes: Lessons from past economic crises, [Online], [Retrieved February 20, 2021] https://blogs.worldbank.org/educatio n/impact-covid-19-labor-marketoutcomes-lessons-past-economiccrises

- Robert Half (2015). Get ready for generation Z. [Online], [Retrieved
February 15, 2021], Available at: https://www.roberthalf.com/blog/the -future-of-work/get-ready-forgeneration- $\mathrm{z}$

- ILO, (2021), ILO Monitor: COVID-19 and the world of work. Seventh edition Updated estimates and analysis, [Online], [Retrieved January 20, 2021], https://www.ilo.org/wcmsp5/groups/ public/---dgreports/---

dcomm/documents/briefingnote/wcm s 767028.pdf

- Ipsos, (2020), [Online], [Retrieved February 20, 2021], https://www.ipsos.com/sites/default/ files/ct/news/documents/2020$10 /$ job-loss-concerns-and-job-skillsreport.pdf

- E.S., (2020), [Online], [Retrieved February 20, 2021], https://ec.europa.eu/info/sites/info/fi les/2020-european semester countryreport-romania ro.pdf pag 17

- $\quad$ Eurofound (2020), Living, working and COVID-19, COVID-19 series, Publications Office of the European Union, Luxembourg., [Online], [Retrieved January 20, 2021], https://www.eurofound.europa.eu/sit es/default/files/ef_publication/field_ef document/ef20059en.pdf

- EUROSTAT, (2021), [Online], [Retrieved February 10, 2021], https://ec.europa.eu/eurostat/statistic $\underline{s-}$

explained/index.php?title=Employmen t in detail - quarterly statistics

- INS, (2020), [Online], [Retrieved February 10, 2021], http://statistici.insse.ro:8077/tempoonline/\#/pages/tables/insse-table

- OECD, (2021) [Online], [Retrieved February 24, 2021], https://www.oecd.org/education/theimpact-of-covid-19-on-educationinsights-education-at-a-glance2020.pdf 